\title{
The Institute of Fiscal Studies' verdict on a sugary drink tax
}

\author{
Peter Scarborough ${ }^{1}$, Adam Briggs ${ }^{1}$, Oliver Mytton ${ }^{2}$, Mike Rayner $^{1}$ \\ ${ }^{1}$ British Heart Foundation Centre on Population Approaches for Non-Communicable Disease \\ Prevention, Nuffield Department of Population Health, University of Oxford \\ ${ }^{2}$ UKCRC Centre for Diet and Activity Research, Department of MRC Epidemiology, University of \\ Cambridge School of Clinical Medicine
}

On Feb 8, 2016, the influential Institute for Fiscal Studies (IFS) released its annual Green Budget-a report aimed at informing the government's March budget.(1) For the first time, their budget report discusses a sugary drink tax and concludes that "the efficacy of [a sugary drink tax] will depend on what products [consumers] switch to and how firms change their prices". The IFS warns that a sugary drink tax could lead to consumers switching to chocolate or that prices of diet drinks could rise thereby weakening the tax's impact on health.

The IFS have based their conclusions on economic theory without reference to the evidence gathered from the evaluation of sugary drink taxes introduced in Mexico, Hungary, Finland, France, and Berkeley (CA, USA). Findings from Mexico show that a sugary drink tax of about $10 \%$ introduced in 2014 resulted in an average reduction of $6 \%$ in sugary drink sales across the year, increasing to a $12 \%$ reduction in December, 2014, with greater reductions in lower socioeconomic groups.(2) Sales figures from Hungary, Finland, and France have also shown measurable decreases in sales of sugary drinks.(3)

Consumption of sugary drinks results in the addition of non-satiating calories to the diet, with little reduction in consumption elsewhere in the diet.(4) This finding suggests that reducing consumption of sugary drinks is unlikely to lead to increases in consumption of substitute food products such as chocolate. Moreover, there is strong evidence that consumption of sugary drinks is associated with obesity, diabetes, dental caries, and cardiovascular disease, with the effects on diabetes and dental caries being independent of total calorie intake.

Evidence from Mexico and Berkeley suggest that taxes of sugary drinks do not influence the price of substitute products such as diet drinks. In Mexico, prices of sugary drinks increased by more than $10 \%$ (ie, more than a $100 \%$ tax pass-on rate), whereas prices of diet drinks were unaffected.(5) Additionally in Berkeley, prices of sugary drinks increased by 0.47 cents per ounce (about a $50 \%$ tax pass-on rate), although diet drink prices were unaffected.(6)

The IFS's Green Budget correctly notes that a sugary drink tax alone will not result in the UK population reducing sugar consumption to meet the target level. But as Public Health England's sugar reduction report recently suggested.(7) this tax could play an important part in a cadre of interventions at the population level. Evidence of the effectiveness of the implementation of sugary drink taxes is available and it is disappointing that the IFS overlooked this evidence in its Green Budget.

All authors contributed equally to this correspondence.

Role of funding source: No funding was sought for this correspondence. 
Declaration of interests: MR and PS are currently undertaking work funded by Public Health England on revising the eat well plate. MR is Chair of Sustain and a trustee of the UK Health Forum. $A B$ and $\mathrm{OM}$ are members of the UK Faculty of Public Health. OM is a member of the UK Health Forum. Each of these organisations has a position statement supporting taxes on sugar sweetened beverages. None of these organisations had any role in the writing of this Correspondence.

\section{References}

1. Emmerson, C, Johnson, P, and Joyce, R. The IFS Green Budget. Institute for Fiscal Studies, London; 2016

2. Arantxa Colchero, M, Popkin, B, Rivera, J, and Ng, S. Beverage purchases from stores in Mexico under the excise tax on sugar sweetened beverages: observational study. BMJ. 2016; 352: h6704

3. Cornelsen, $L$ and Carriedo, A. Health-related taxes on foods and beverages. Food Research Collaboration. http://foodresearch.org.uk/wp-content/uploads/2015/06/Food-andbeverages-taxes-final-amended.pdf; 2015.

4. DiMeglio, D and Mattes, R. Liquid versus solid carbohydrates: effects on food intake and body weight. Int J Obes Relat Metab Disord. 2000; 24: 794-800

5. Arantxa Colchero, M, Salgado, JC, Unar-Munguia, MM, Ng, S, and Rivera-Dommarco, J. Changes in prices after an excise tax to sweetened sugar beverages was implemented in Mexico: evidence from urban areas. PLoS One. 2015; 10: e0144408

6. Falbe, J, Roas, N, Grummon, A, and Madsen, K. Higher retail prices of sugar-sweetened beverages 3 months after implementation of an excise tax in Berkeley, California. Am J Public Health. 2015; 105: 2194-2201

7. Public Health England. Sugar reduction: the evidence for action. London. https://www.gov.uk/government/uploads/system/uploads/attachment data/file/470179/S ugar reduction The evidence for action.pdf; 2015. 